July 2020

\title{
Beyond Populism: The Psychology of Status-Seeking and Extreme Political Discontent
}

\author{
Michael Bang Petersen* \\ Mathias Osmundsen \\ Alexander Bor \\ Department of Political Science, Aarhus University \\ * Corresponding author: michael@ps.au.dk
}

\begin{abstract}
Modern democracies are currently experiencing destabilizing events including the emergence of demagogic leaders, the onset of street riots, circulation of misinformation and extremely hostile political engagements on social media. Some of the forms of discontent are commonly argued to be related to populism. In this chapter, however, we argue that the evolved psychology of statusseeking lies at the core of this syndrome of extreme political discontent. Thus, social status constitutes one of the key adaptive resources for any human, as it induces deference from others in conflicts of interest. Prior research has identified two routes to status: Privilege acquired through service and dominance acquired through coercion. We argue that extreme political discontent involves behaviors aimed at dominance through engagement in either individual aggression or in mobilization processes that facilitate coalitional aggression. Consistent with this, we empirically demonstrate that measures of status-seeking via dominance correlate with indices of a large number of extreme forms of political discontent and do so more strongly than a measure of populism. Finally, we argue that the reason why dominance strategies become activated in the context of modern democratic politics is that increased inequality activates heightened needs for status and, under such conditions, dominance for some groups constitutes a more attainable route to status than prestige.
\end{abstract}

Chapter prepared for The Psychology of Populism, eds. Joseph Forgas, Bill Crano, and Klaus Fiedler. Routledge.

This research was founded by a grant from The Carlsberg Foundation to MBP. 
Populist leaders and parties have recently gained electoral traction such as, Donald Trump in the United States, Viktor Orban in Hungary and radical right-wing parties across multiple European countries. This development is widely feared as a central danger for modern Western democracies (Levstsky \& Ziblatt, 2018) and, indeed, the emergence of these parties and leaders have cooccurred with a range of troubling developments: Hateful debates on social media platforms (Grubbs et al., 2019), intensified belief in and circulation of conspiracy theories and other "fake news" (Miller et al., 2016; Vosoughi et al., 2018) and even the onset of violent protests, for example, in France and the United States (see also Marcus, this volume; Bar-Tal, this volume).

Correlation, however, is not causation. While the emergence of populism has co-occurred with these developments, they may not necessarily spring from the same psychological motivations. Specifically, while they are all forms of political discontent, we argue that the most extreme forms of discontent - such as the endorsement of political violence - emerges from a distinct set of motivations. Building on psychological research on status-seeking, we argue that at the core of extreme political discontent are motivations to achieve status via dominance, i.e., through the use of fear and intimidation (Cheng et al., 2013). Essentially, extreme political behavior reflects discontent with one's own personal standing and a desire to actively rectify this through aggression (see also Hogg, this volume). While populism also reflects frustrated motivations, we argue that these are more related to more submissive and passive forms of discontent. Finally, we argue that this understanding of the deeper roots of extreme political discontent is important if modern democracies are to move towards less polarization. 


\section{The Psychology of Status-Seeking}

For group-living animals, social status in the form of a higher placement in the hierarchy is a key adaptive resource that promotes survival and reproduction. Among humans, evolutionary psychologists and others have documented this in a myriad of ways using both evolutionary psychology, historical data, ethnographic data and data from industrialized societies (Sidanius \& Pratto, 2001). Higher status individuals are more attractive and shire more and healthier offspring (von Rueden et al., 2011). As extreme examples of this genetic and evolutionary analyses suggest that substantial proportions of current populations in specific regions can be traced back to single individuals such as, for example, Genghis Khan in East Asia (Zerjal et al., 2003).

More broadly, we can conceptualize status as a meta-resource that determines the flow of other, more tangible resources, especially when access to these resources is contested. For most animals, the allocation of contested resources is determined by relative differences in physical strength and size. However, for humans and other ultrasocial animals, the ability to mobilize conspecifics on your behalf is even more important (Tooby et al., 2006). Two people can almost always prevail over any single person, independently of their individual strength. Consistent with this, a line of research has consistently demonstrated that we intuitively think of individuals in well-coordinated groups as more formidable adversaries (Fessler \& Holbrook, 2016) and, hence, as someone to avoid engaging in conflict with.

Social status is key in this respect. Social status implies social influence and individuals with higher status can more easily direct the course of action that others take (von Rueden et al., 2011). This allows for mobilizing others on behalf of the self and for demobilizing potential adversaries. Essentially, social status is a resource that allows you to win contests without having to fight. 
Because of the evolutionarily recurrent importance of social status, a large number of psychological mechanisms in the human mind are specifically designed for status-acquisition. These mechanisms underlie at least two broader classes of strategies: Prestige and dominance (Cheng et al., 2013). Prestige-based strategies involve the cultivation of talents and skills that are valuable for others and, hence, prestige-based status is based on a reciprocal relationship wherein status is granted in exchange for service. Dominance-based strategies, in contrast, involves the use of "fear and intimidation" in order to get recognition from others.

A craving for status is universal but individuals will differ in whether they follow prestigeor dominance-based strategies to acquire it. For example, individuals with high physical formidability or low trait empathy are better able to navigate conflicts pursuing dominance-based strategies (Petersen \& Laustsen, 2019). This can be further reinforced by situational factors. Individuals with high degrees of human capital, for example, can more easily utilize a prestigebased strategy. Individuals with less socially valued skills, in contrast, are pushed towards dominance-based strategies.

\section{Political Discontent and The Tactics of Dominance-Based Strategies}

The psychology of dominance is likely to underlie current-day forms of extreme political discontent - and associated activism - for two reasons: First, radical discontent is characterized by verbal or physical aggression, thus directly capitalizing on the competences of people pursuing dominance-based strategies. Second, current-day radical activism seems linked to desires for recognition and feelings of "losing out" in a world marked by, on the one hand, traditional genderand race-based hierarchies, which limits the mobility of minority groups and, on the other hand, globalized competition, which puts a premium on human capital (Kitschelt, 2002; Kriesi \& 
Schulte-Cloos, 2020). Extreme discontent, in other words, is a phenomenon among individuals for whom prestige-based pathways to status are, at least in their own perception, unlikely to be successful. Despite their political differences, this perception maybe be the psychological commonality of, on the one hand, race- or gender-based grievance movements and, on the other hand, white lower-middle class right-wing voters.

Broadly speaking, dominance-based strategies for status-acquisition involve, at least, two classes of aggressive tactics: Direct and indirect aggression. Direct aggression is the use of verbal or physical violence, or threats thereof, directed against the perceived adversary. In the context of current-day political discontent, such adversaries can be authorities or opposing political groups and the specific tactics can cover a wide-range of behaviors from direct confrontations in the streets to hostile social media interactions.

Indirect aggression is an even more complex set of specific tactics. Indirect aggression often involves gossiping with the aim of diminishing the value of the target in the eyes of others (Archer \& Coyne, 2005) but indirect aggression can also take the form of attempts to mobilize others for aggression directed against adversaries. Mobilization is an extraordinarily difficult process as it not only requires the alignment of preferences ("we need to do X...") but also the alignment of attention ("...and we need to it now!") (Petersen, 2020; Tooby et al., 2005). Furthermore, mobilization for intergroup aggression is even more difficult, as the needed level of mobilization is always relative to the enemy: You need your group not just to be well-coordinated but better coordinated than the outgroup (Laustsen \& Petersen, 2015). Thus, in group conflicts, the better coordinated group is more likely to prevail. Accordingly, there are several lines of research that suggests that aggression from other groups activates accelerated motivations to engage in mobilization processes (De Dreu et al., 2016). 
There are multiple ways to facilitate aggressive mobilization but three have received significant attention: Moralization, rumor-sharing and followership (Petersen, 2020). Moralization refers to the process of recasting or framing a position as moral or immoral, i.e., either in accordance or discordance with the group's overarching social norms. Moral principles are principles that are just from the perspective of a neutral spectator and, hence, moralization is a key strategy to draw otherwise neutral audiences into a conflict, as moralization entails the message that the conflict is relevant from their perspective as well. Thus, a common mobilization tactic is to describe one's own position as moral and the position of an adversary as immoral. This can mobilize people not only on behalf of one's own position by inducing the perception that their interests are aligned with the advocated position but can also have the additional advantage of demobilizing people who might otherwise support the position of the adversary. If a position is broadcasted as moral, fear of moral condemnation can demotivate others from opposing it.

Rumor-sharing has always played a significant role in conflicts. For example, in a systematic review of violent ethnic riots, Horowitz (2001: 74) observed that "Concealed threats and outrages committed in secret figure prominently in pre-riot rumors. Rumors are (...) embedded in the riot situation, because they are satisfying and useful to rioters and their leaders. (...) Rumor is likely to prevail over accurate information. (...) Rumor prevails because it orders and organizes action-in-process." Consistent with this description, psychological studies of conspiracy theories and misinformation show that people are likely to both believe and share rumors that portray enemy groups in a negative way (Miller et al., 2016; Osmundsen et al., 2020; see also Kreko, this volume). This is interpretable as instrumental or motivated attempts to broadcast information that will mobilize audiences against the adversary. Thus, rumors used in intergroup conflict from ethnic riots to modern politics are extraordinarily similar in that they all emphasize that the adversary is 
evil, powerful and about to act, creating a sense of urgency in receivers to engage in counteractivities. One striking example was the Pizza Gate conspiracy shared by Republicans during the 2016 Presidential US election, arguing that leading Democrats were holding abused children hostage in the basement of a named pizzeria in Washington DC. For one person, the sense of urgency created was strong enough for him to come to the pizzeria with an automatic rifle, intending to save the children.

Finally, leaders play a central role in mobilization processes. Whereas moralization and information-sharing are attempts to organize groups from the bottom-up, leaders are crucial vehicles for organizing groups from the top. Leaders can facilitate collective action by sanctioning free-riders and by acting as first movers (Glowacki \& von Rueden, 2015). Importantly, however, leaders do not emerge from thin air. Rather, in many if not most human groups, leaders emerge because a substantial proportion choose to follow them. In this way, followership decisions can play a central role. Essentially, individuals invested in mobilizing others for aggressive projects can strategically choose to follow leaders who they believe will escalate conflicts and endorse aggressive solutions. Converging lines of research suggest that strong, dominant leaders cater to such motivations and psychological studies show that primes of intergroup conflict increases motivations to follow dominant leaders (Petersen \& Laustsen, 2020; see also Forgas \& Lantos, this volume).

\section{Beyond Populism: Extreme Discontent as a Dominance Syndrome}

These arguments suggest that status-seeking motivations and, in particular, dominance-oriented status-seeking could be at the center of a large number of discontent-related forms of political activism such as endorsement of political violence, hostile interactions on social media, excessive 
moralization, sharing of and believing in misinformation and the promotion of aggressive leaders. Consistent with this, past research has demonstrated that individual differences in status-seeking or dominance motivations are highly predictive of participation and support of political violence (Bartusevicius et al., 2020), political hostility both online and offline (Bor \& Petersen, 2019), moral grandstanding (Grubbs et al., 2019), motivations to share conspiracy theories (Petersen et al., 2020) and preference for dominant leaders (Laustsen \& Petersen, 2017). Thus, based on the background of these existing studies, we contend that motivations to gain status via dominance is the underlying syndrome, activated in the context of current-day politics, that fuels these extreme expressions of political discontent.

These motivations are most likely distinct from some of the motivations underlying populism, as this concept is commonly understood. Populism involves a combination of eliteskepticism and a belief in wisdom of "the people" or some form of common will (Marchlewska et al., 2018). Some studies suggest that populism correlates with a lack of agreeableness (Bakker et al., 2016), feelings of anger (Rico et al., 2017) and collective narcissism (see also Golec de Zavala, this volume). These factors are also likely to be related to status-seeking motivations and this could lead to the expectation that there is some overlap between populist support and status-seeking motivations. However, other studies have argue that the key psychological precursors of populist support include authoritarianism (Norris \& Inglehart, 2019; but see Dunn, 2015), traditionalism (Sniderman et al., 2014) and the need to conform to particular identities (Salmela \& Scheve, 2017), as, for example, reflected in the nationalism that is part of many right-wing populist agendas (Dunn, 2015). Furthermore, and consistent with the emphasis on "the people", evidence suggests that populist voters often are egalitarian and support redistributive policies (Malka et al., 2020; Sniderman et al., 2014). Both the orientation towards group conformity and equality are in stark 
contrast to dominance motivations. In contrast to conformity, dominance leads to self-promotion. In contrast to equality, dominance leads to support for steep hierarchies. While many extreme forms of political discontent are temporally correlated with the emergence of populism in Western democracies (and, potentially, are linked to the same underlying structural causes), we thus suggest that populism and extreme political discontent are nonetheless psychologically distinct phenomena.

\section{Methods and Design}

Our data came from a survey fielded on the Lucid platform in March 2020. Lucid, the largest US marketplace for online convenience samples, uses quota sampling to approximate national representativeness. Researchers increasingly turn to online convenience samples to test theories about human psychology, and while Lucid is a new and probably less well-known source of online respondents, early results appear very promising: "[D]emographic and experimental findings on Lucid track well with US national benchmarks" (Coppock and McClellan 2019, 1; see also Graham 2020).

We recruited 1,030 US citizens to participate in our study. We excluded 233 participants who failed at least one out of three attention checks, and another twelve participants with missing values on at least one of the central variables described below. The attention checks were designed to capture (1) response set (i.e.,, providing the same answer regardless of the question, sometimes referred to as "straight lining"), (2) inattention to instructions and (3) so-called "survey trolling", i.e., insincere reporting of extreme behavior (Lopez \& Hillygus, 2018). Given the nature of some of the questions, we deemed this three-fold approach necessary. It should be noted, however, that the substantial conclusions do not change if we include all respondents in the analyses. 
Of the remaining 795 participants, 54\% were females and the average age was 46 years old (standard deviation $(\mathrm{SD})=17$ years). In terms of education, 3\% reported "Less than high school" as their highest completed degree, 15\% were "High school graduate[s]," 26\% selected "Some college, but no degree," $12 \%$ had a "2 year college degree," $24 \%$ said "4 year college degree," and $9 \%$ had a "Graduate or professional degree" category. The median household income before taxes was “ $\$ 40,000$ to $\$ 49,999$." In the study, $75 \%$ of participants identified as white/Caucasian.

Our study had three main goals. The first goal was to test if status-seeking is a driver of a range of manifestations of extreme political discontent. The second goal was to directly compare the discontent-related correlates of status-seeking and populism and to assess whether these are the same or different. Finally, the third goal was to show that the association between statusseeking and political discontent was the product of dominance strategies rather than prestige. We asked all survey participants to answer questions related to these key variables.

Status-seeking motivations. Our key independent variable is status-seeking motivations, which we measure with a validated Status-Driven Risk Taking scale from Ashton and colleagues (2010). Informed by evolutionary psychological research on competitive risk-taking, the authors developed the scale to measure the pursuit for money, power and social prestige (ibid. 734). The Status-Driven Risk Taking scale asks participants to indicate on seven-point scales if they agree or disagree with fourteen statements like "I would enjoy being a famous and powerful person, even if it meant a high risk of assassination" and "I would rather live a secure life as an ordinary person than risk everything to be "at the top" (reverse coded). The statements formed a reliable battery $(\alpha=.91)$ and were summed and rescaled to form an index ranging from 0 to 1 , with higher values indicating greater status-driven risk taking $(\mathrm{M}=.30, \mathrm{SD}=.21)$. 
Populism. To measure populist attitudes, we asked participants to complete the short sixitem version of the populist attitude scale developed by Castanho Silva and colleagues (2018) (e.g., "The government is pretty much run by a few big interests looking out for themselves"; Response on seven-item scale: $0=$ Strongly Disagree $; 1=$ Strongly Agree; $\alpha=.73, \mathrm{M}=.50, \mathrm{SD}=.14)$. To enable us to isolate the distinct effects of status-seeking, all analyses adjust for this populism measure. In addition, we adjust for a comprehensive set of sociodemographic factors: Gender, age, educational level, income level and ethnicity.

Dominance and Prestige. As previously discussed, humans can follow two distinct paths to social status, where the dominance path uses intimidation, aggression and fear to attain status while the prestige route leads to social status through the possession of skills and resources that others value. Our argument entails that expressions of political discontent - especially its extreme forms, which we examine here -- flows from a desire to obtain status through dominance rather than prestige. To assess this, we measure both dominance- and prestige-related motivations, using slightly modified forms of two scales from Chen, Tracy and Henrich (2010). The Dominance scale asks participants how accurately eight statements describe them (e.g., "I enjoy having control over others," "Others know it is better to let me have my way"; response on seven-point scale: $0=$ Strongly Disagree $; 1=$ Strongly Agree. $\alpha=.80, \mathrm{M}=.36, \mathrm{SD}=.19)$. The Prestige scale asks about the accuracy of nine items ("People I know respect and admire me", "Others seek my advice on a variety of matters"; response on seven-point scale: $0=$ Strongly Disagree; $1=$ Strongly Agree.$\alpha$ $=.76, \mathrm{M}=.61, \mathrm{SD}=.6)$.

Political Discontent. Political discontent, our key dependent variable, can take many forms. As discussed above, its more extreme manifestations include a variety of attitudes and behaviors: Support for, and participation in, violent political riots and protests; political sympathies for 
"strong" leaders with a distaste for democratic rules of conduct; the sharing of political misinformation and blatant lies about political elites; and disruptive behavior in online political discussions. To fully grasp the nature and shape of extreme political discontent, we included as many of these different strands as possible.

We first measured Political Violence Intentions with a revised ten-item version of the scale from Moskalenko and McCauley (2009; see Gøtsche-Astrup, 2019; e.g., "I would attack police or security forces if I saw them beating members of my group," response on seven-point scale: $0=$ Strongly Disagree; $1=$ Strongly Agree: $\alpha=.91, \mathrm{M}=.29, \mathrm{SD}=.22$ ). We next measured Strong Leader Preferences with Sprong and colleagues' (2019) three-item scale (e.g., "We need strong leadership in order to overcome societies' difficulties"; response on seven-point scale: $0=$ Strongly Disagree $; 1=$ Strongly Agree: $\alpha=.88, \mathrm{M}=.83, \mathrm{SD}=.19)$. Next, we included measures of beliefs in and intentions to share Hostile Political Rumors from Petersen, Osmundsen and Arceneaux (2020). Their measures ask participants to read six rumors denigrating mainstream political actors from both the political left and right, and then to state whether participants agree (1) the rumors are true, and whether (2) they would want to share the rumors on social media. We combined participants' responses into additive scales measuring beliefs the rumors were true (response on seven-item scale: $0=$ Strongly Disagree $; 1=$ Strongly Agree; $\alpha=.63, \mathrm{M}=.39, \mathrm{SD}=.20)$ and measuring intentions to share the rumors (response on seven-item scale: $0=$ Strongly Disagree; 1 $=$ Strongly Agree $; \alpha=.88, \mathrm{M}=.26, \mathrm{SD}=.25)$.

Our final two measures of political discontent came from Grubbs and colleagues (2019): Moral grandstanding and Political/Moral conflict. Moral grandstanding - the use of moral talk in debates to enhance one's social status and belittle others - was measured with a four-item scale (e.g., "I share my moral/political beliefs to make people who disagree with me feel bad"; Response 
on seven-item scale: $0=$ Strongly Disagree $; 1=$ Strongly Agree $; \alpha=.90, \mathrm{M}=.27, \mathrm{SD}=.25$ ). Grubbs et al. (2019) originally created two subscales to measure moral grandstanding motivations. We focus on their Moral Grandstanding: Dominance striving subscale, which is the theoretically relevant one. Furthermore, we measured Political/Moral conflict - the tendency to launch into online political fights with others - with Grubbs and colleagues' (2019) seven-item scale (e.g., "Over the past twelve months, I have... gotten into fights on social media because of my political/moral beliefs"; Response on four-item scale: $0=$ Never/Not at all; $1=$ Several times; $\alpha=$ $.91, \mathrm{M}=.24, \mathrm{SD}=.27)$

\section{Status-Seeking, Populism and Extreme Political Discontent}

We begin our exploration by asking: Were status-seeking motivations associated with extreme political discontent? Did people with a desire to improve their social status express stronger political discontent and dissatisfaction than people without that same drive for status? In a word: Yes. The motivation to attain status was strongly associated with the majority of ways extreme political discontent manifests itself. Figure 1 presents the results. It shows estimated ordinary least squares regression coefficients from models that regress the six measures of political discontent on status-seeking motivations and our set of sociodemographic covariates. To conserve space, the figure only includes the coefficients for status-seeking motivations and populist attitudes. We scale all variables to range from 0 to 1 , which allows us to interpret the coefficients as the change in percentage points of the full scale of the dependent variable as we move from the low to the high extreme of the independent variable.

Figure 1 reveals that participants with a desire for status expressed higher levels of political discontent on five out of the six measures compared to participants with low status aspirations. 
Status-seeking was positively associated with intentions to engage in political violence ( $\beta_{\text {violent }}$ activism $=.50, \mathrm{p}<.05)$, beliefs that hostile political rumors about mainstream politicians are true $(\beta$ believe hostile rumors $=.21, \mathrm{p}<.05)$, intentions to share those same hostile rumors on social media $(\beta$ believe hostile rumors $=.45, \mathrm{p}<.05)$, the inclination to demonstrate moral and political superiority in online discussions $(\beta$ moral grandstanding $=.40, \mathrm{p}<.05)$, and, finally, readiness to fight over political and

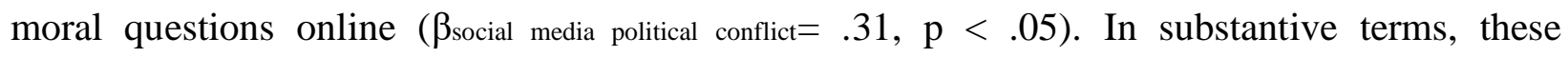
associations were consistently strong: Moving from the lowest to the highest level of statusseeking aspirations was associated with a 20-50 percentage points increase in political discontent, varying slightly depending on which of the five aspects of discontent we focus on. Together, these findings are consistent with our claim that status-seeking motivations are critical for understanding citizens' political dissatisfaction and disengagement.

Figure 1 also offered one result that runs counter to our hypothesis. High-status participants disapproved of one particular manifestation of political discontent: Strong political leaders ( $\beta$ strong leader $=-.13, \mathrm{p}<.05)$. A, theoretically derived, possibility is that those who crave status hesitate to endorse strong leadership, because strong leaders may hamper their chances of climbing the social ladder. At the same time, it should be noted that the scale of leadership preferences is highly skewed distribution of leadership preferences - almost all of the participants preferred strong political leadership - which leaves us with little variation to explain. Of note here is that we gathered the data in the midst of the coronavirus epidemic where strong leadership was in high demand.

Finally, consistent with our argument, Figure 1 shows that only a limited variety of political discontent is widespread among citizens who support populist ideas. Populist attitudes were only positively associated with three of six manifestations of political discontent, and not the ones that 
arguably reflect the most "extreme" discontent, like support for violence. One noteworthy finding that we highlight here was that populism -- unlike status-seeking -- was positively associated with preferences for strong political leadership. This comports with earlier work highlighting how approval of strong leadership is one characteristic that various conceptions of populism have in common (Mudde \& Kaltwasser, 2014), and it suggests that populism may indeed be associated with such narrow, moderate forms of political discontent.

This latter finding notwithstanding, we maintain that the results presented so far firmly support our hypothesis. The drive for attaining status seems to be at the nexus of various manifestations of extreme political discontent that many democracies currently witness. Further, the results make clear that status-seeking motivations may be a more important mechanism in understanding political dissatisfaction and political polarization than other usual culprits, like populist sentiment. 


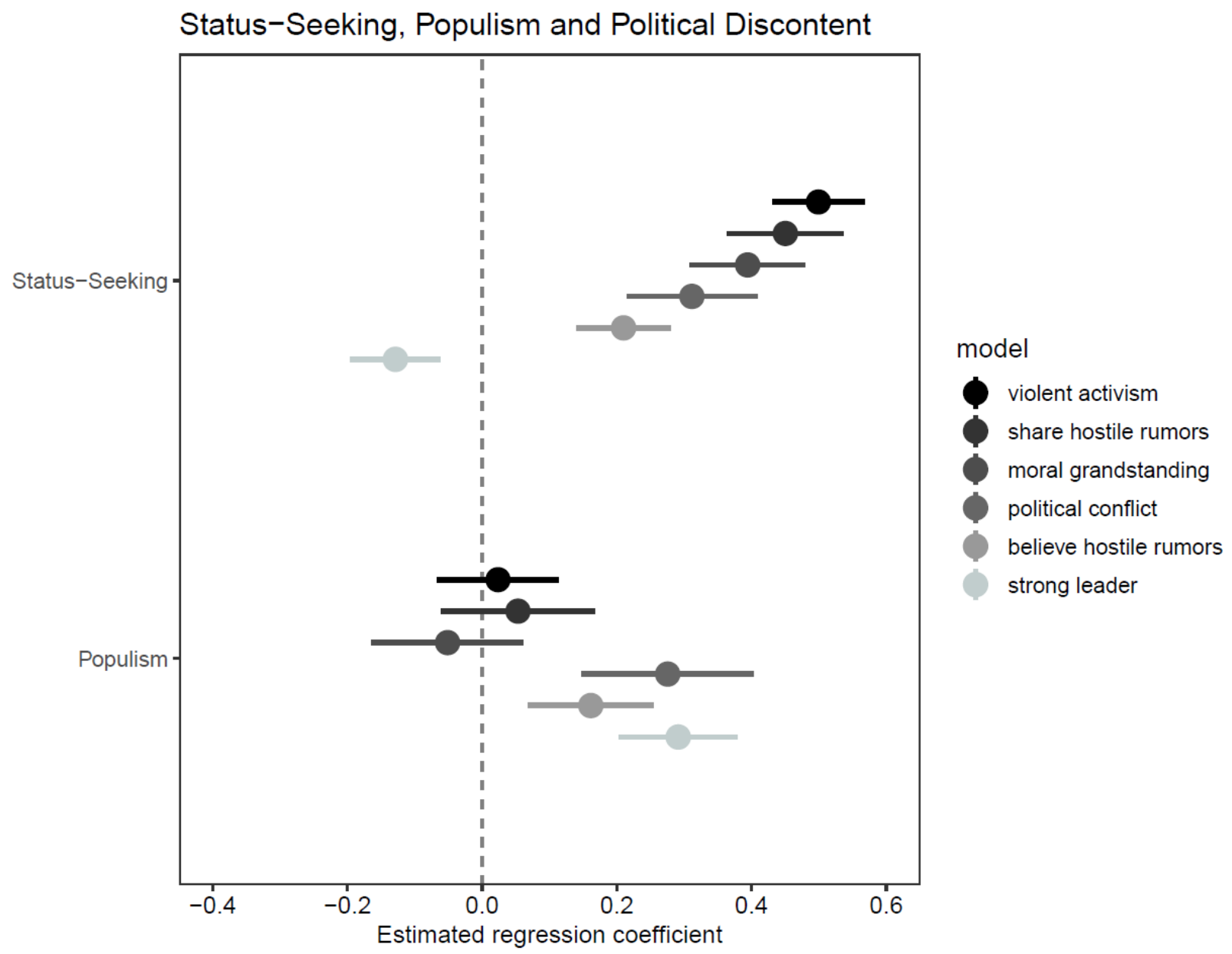

Figure 1. Estimated regression coefficients from models that regress six measures of political discontent on status-seeking motivations and populist attitudes. Unstandardized OLS regressions coefficients with $95 \%$ confidence intervals. All variables are scaled to range from 0 to 1 , allowing us to interpret the unstandardized regression coefficients as the change in percentage points of the full scale of the dependent variable as we move from the low to the high extreme of the independent variable. The models adjust for gender, age, educational level, household income level, and ethnicity.

\section{Dominance, prestige and extreme political discontent}

The analysis so far has shown that status-seeking motivations are associated with political discontent. We devote the remaining part of the analysis to determine if extreme political discontent - with its emphasis on individual and collective action involving aggression and antagonistic encounters with political foes - reflects a drive for status rooted primarily in dominance motives rather than prestige. 
To understand whether self-perceived dominance rather than self-perceived prestige contributes more to explaining variation in political discontent, we now turn to Figure 2. It presents estimated ordinary least squares regression coefficients from models that regress the six measures of political discontent on dominance, prestige and a set of covariates, including populist attitudes. Like before, we facilitate interpretation by scaling the variables to range from 0 to 1.

What is most striking in Figure 2 is how differently dominance and prestige mapped onto political discontent. While Status-Driven Risk-Taking and dominance motivations were not perfectly correlated $(r=.55)$, results for dominance were almost identical to those from the analysis on status-seeking motivations: Participants who viewed themselves as dominant expressed much stronger political discontent on five out of the six measures than low-dominance participants;

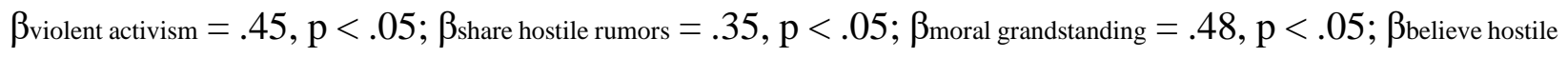
rumors $=.20, \mathrm{p}<.05$. Tellingly, the one exception was that dominant participants were more disapproving of strong leaders $(\beta$ strong leader $=-.13, \mathrm{p}<.05)$. Again, a likely interpretation is that dominant individuals do not view the appointment of strong leaders as a viable strategy for them to attain status.

What about prestige and political discontent? Results were almost a mirror image of the dominance findings. Prestigious individuals were much less discontent and expressed higher political satisfaction on four out of six manifestations of political discontent - moral grandstanding $(\beta$ moral grandstanding $=-.30, \mathrm{p}<.05)$, support for violent activism $(\beta$ violent activism $=-.20, \mathrm{p}<.05)$, political and moral conflict $\beta$ political conflict $=-.15, \mathrm{p}<.05)$ and sharing of hostile rumors $\left(\beta_{\text {sharing hostile rumors }=-}\right.$ $.09, \mathrm{p}=.076)$. They also generally supported strong political leadership $(\beta$ strong leadership $=.23, \mathrm{p}<$ .05). While these findings suggest that prestige may indeed play a role in affecting political discontent - with high prestige dampening discontent - the size of the estimated coefficients for 
prestige were generally smaller than the coefficients for dominance. This implies, in line with our assumptions that dominance, not prestige, is the more relevant mechanism in understanding how status-seeking can translate into various forms of extreme political discontent (the exception being preferences for strong leadership).

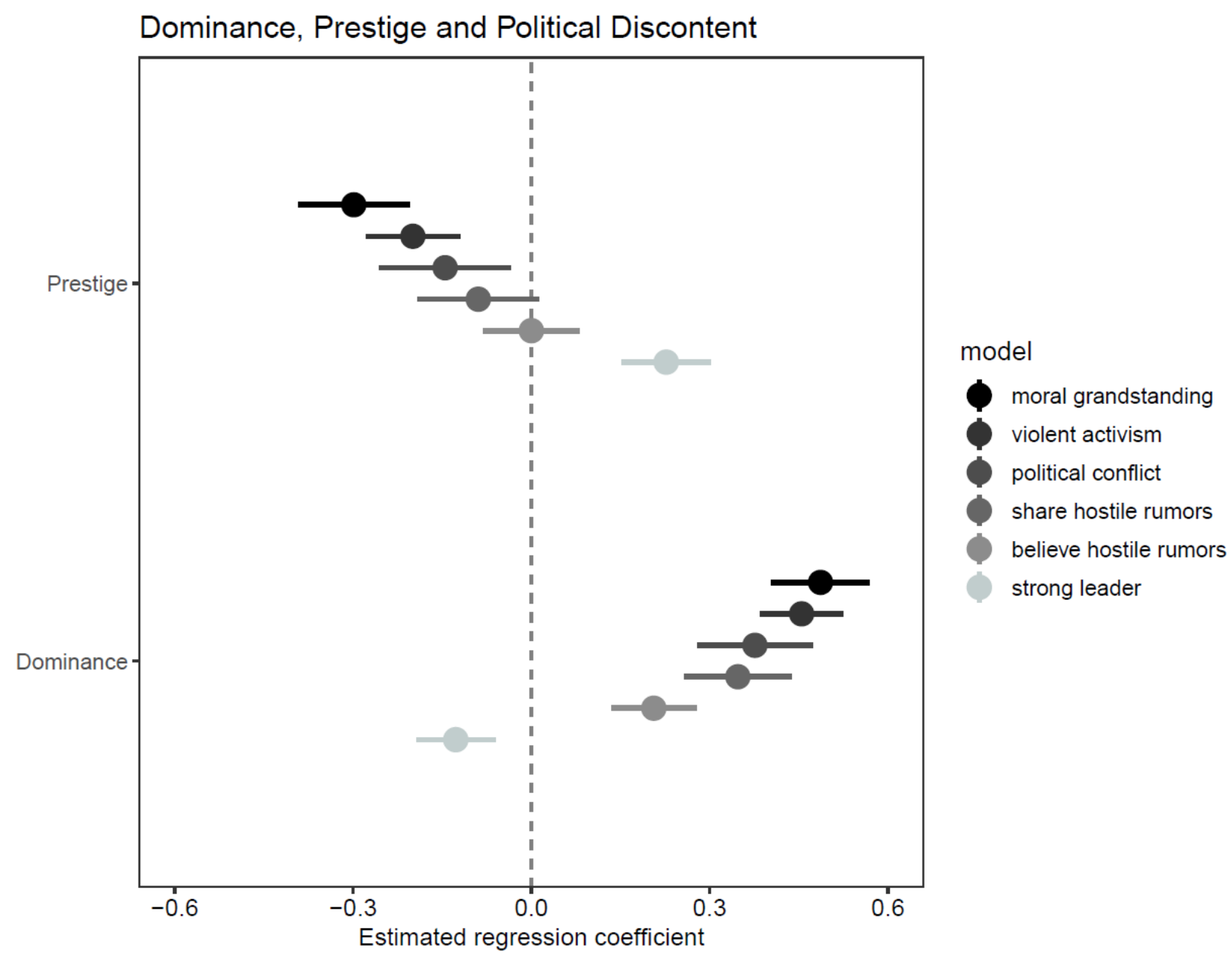

Figure 2. Estimated regression coefficients from models that regress six measures of political discontent on dominance and prestige. Unstandardized OLS regressions coefficients with $95 \%$ confidence intervals. All variables are scaled to range from 0 to 1 , allowing us to interpret the unstandardized regression coefficients as the change in percentage points of the full scale of the dependent variable as we move from the low to the high extreme of the independent variable. The models adjust for gender, age, educational level, household income level, populist attitudes, and ethnicity. 


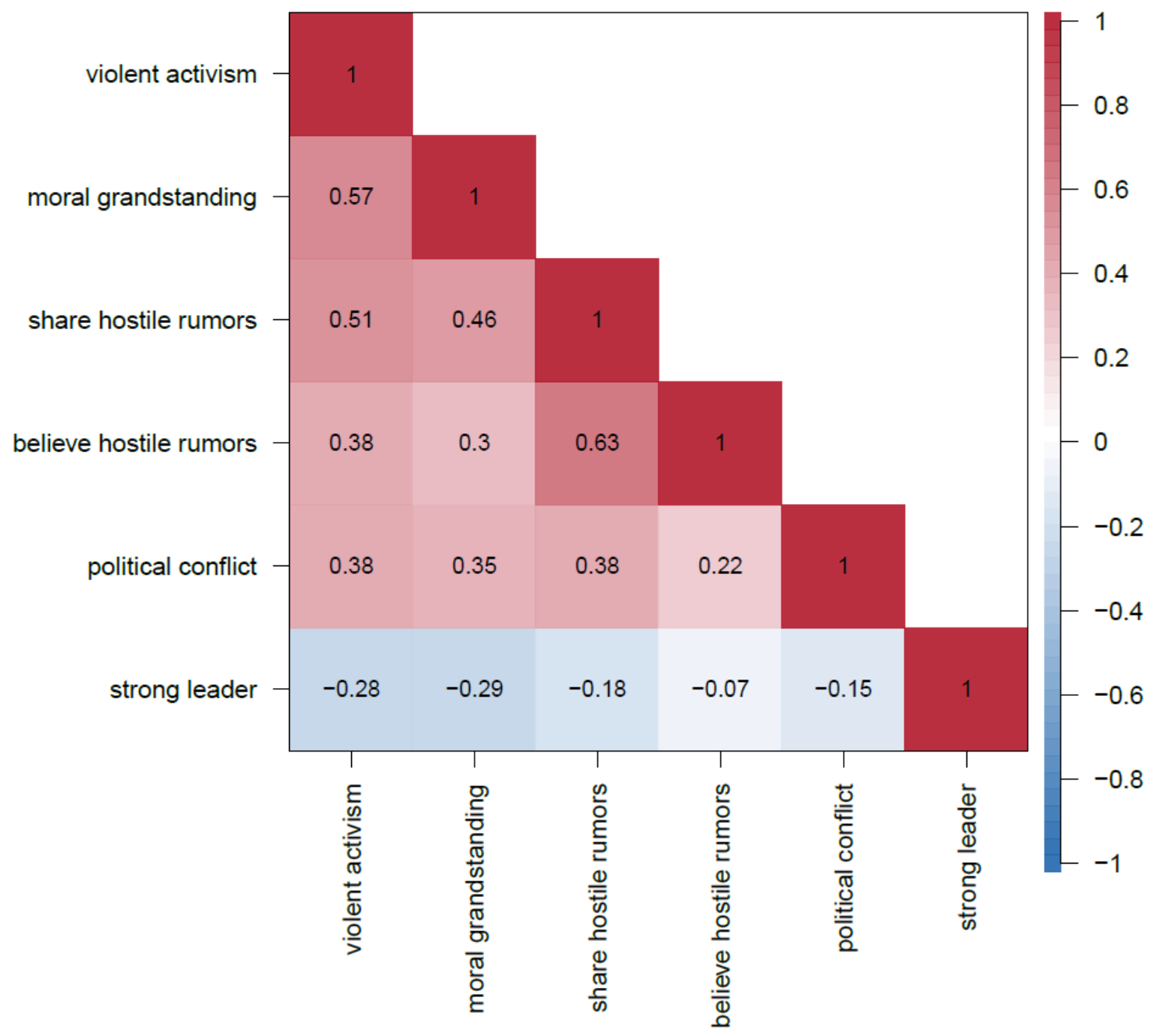

Figure 3. Pearson's r correlation between six manifestations of political discontent.

\section{Active and Passive Forms of Extreme Political Discontent}

Overall, dominance motivations have a unique strong and positive relationship to support for political violence, moralizing and the sharing of hostile political rumors. Populism has a unique positive relationship to support for strong, authoritarian leaders. Beliefs in hostile political rumors and engagement in political conflict on social media are related to both populism and dominanceseeking. 
These divisions cohere with the patterns of intercorrelations between the forms of discontent presented in Figure 3. First, there is a highly correlated cluster of forms of discontent involving extreme and highly active forms of behavior: Violent activism, moral grandstanding and rumor-sharing. Then there is a cluster with lower but positive intercorrelations involving belief in hostile political rumors and involvement in political conflicts on social media. Finally, support for strong, dominant leaders is negatively related to all the other forms of discontent.

One possible interpretation of these observations is that populism fuels a cluster of more passive forms of discontent. Populists privately believe that the political system is corrupt and they promote strong leaders who can take care of that problem for them (see also Bar-Tal, this volume; Marcus, this volume). They do become engaged in hostile interactions on social media but, perhaps, they are less likely to initiate those themselves and rather become disentangled in them when they are called out by other social media users. Dominance-motivated individuals, in contrast, are motivated to take on the source of their discontent themselves and this fuels the most active forms of dissent: Behavioral intentions to fight the police; a willingness to not only believe that the system is corrupt but to share information about it with wide audiences on social media; and a habit of actively using moralization to suppress the views of others.

Psychologically, this seems to reflect two very different strategies of navigating hierarchies. As discussed, dominance reflects motivations to reach the top of the hierarchy by the use of force and intimidation. These motivations stand in contrast to motivations to use prestige as a way to gain status. Importantly, however, dominance motivations also stand in contrast to a depressed level of status-seeking motivations altogether. Thus, while the evolutionary sciences suggest that status is an adaptive resource that is universally beneficial, this line of work also acknowledges that there are trade-offs involved. For individuals with limited possibilities of 
advancing in the hierarchy, it may be advantageous to accept a subordinate position in exchange for social harmony and favors from higher-ranking individuals (Dawkins, 2016; De Waal, 1996). Such dynamics may lie at the core of the psychology of populists: They are discontent with the current system but their alternative political vision is not one in which they personally are placed at the top of the hierarchy. Rather, they seek to promote those others to a top position that they believe will selectively benefit them and people like them. In contrast, those who engage in more active forms of discontent are fueled by a personal craving for power. Consistent with this, we find that populism and Status-Driven Risk Taking is only weakly (and negatively) correlated at $\mathrm{r}=-.08$.

\section{The Deep Roots of Extreme Discontent}

There is evidence that extreme forms of political discontent are on the rise in, at least some, Western democracies (Turchin, 2016). Examples include protests that turn into riots, terrorism in both its religious and political forms and other frustration-based extreme events such mass shootings. Psychological research demonstrates that the use of aggressive status-seeking strategies is a reflection of both personality and situational factors (Gøtzsche-Astrup, 2019). It is unlikely that a rise in extreme discontent reflects a general increase in dominance personality dispositions, but multiple lines of research present evidence for an increase in situational factors that could potentially lead to more aggressive activism.

Media studies point to changes in the media landscape. For example, some studies argue that an increasing reliance on cable TV has created political content bubbles that could lead to a lack of understanding of political adversaries and, as consequence, an increased political polarization. In the United States, Fox News has received significant attention and some studies do suggest that exposure to Fox News is related to polarization (Martin \& Yurukoglu, 2018; 
Morris, 2005). Other studies focusing on more recent media development argue that the advent of social media increases aggression and lowers empathy, due to the lack of face-to-face interaction (Baek et al., 2012).

Studies in political science often point to the role of political leaders in creating an increasingly uncivil public discourse (Mutz, 2016) and find evidence that leaders in the United States, specifically, have used increasingly aggressive rhetoric (Neal, 2020). Other political science studies point to a process called sorting that entails that there is an increased convergence of partisanship with socio-demographic factors such as race or religiosity (Mason, 2015). Sorting fuels political polarization as animosity between partisan groups map onto pre-existing and potentially deeper cleavages between socio-demographic groups.

All these explanations are important, have theoretical value and undeniable empirical leverage. Yet, at the same time, they may fail to provide a general understanding of the roots of current-day discontent. Some are US-centric, highlighting idiosyncratic features such as Fox News. Some are focusing on very recent events, such as the advent of social media, even though polarization has been increasing for several decades (Neal, 2020; Turchin, 2016). Finally, explanations focusing on political mobilizations along racial or religious lines could plausibly be perceived as symptoms rather than causal drivers of increasing discontent.

When looking beyond the surface to the potential deeper structural factors that could push discontent upwards across countries and decades, researchers have especially focused on inequality. It is a fact that economic inequality has been rising across Western democracies over the past decades (Alderson \& Nielsen, 2002). While inequality is sometimes argued to induce a conflict between those at the bottom and those at the top of the hierarchy, it is important to understand that inequality also creates conflict at every step of the societal ladder. Essentially, 
inequality "stretches" the hierarchy and, hence, increases status-competition for all (Turchin 2016). Consistent with this, psychological research shows that perceptions of inequality fuels statusseeking motivations (Sibley et al., 2007). Furthermore - and consistent with the link between status-seeking and extreme forms of discontent - analyses of historical data demonstrate that rising inequality and increased status-competition among elites are highly predictive of the level of political instability in a given time period (Turchin, 2016).

Inequality shifts public discourse from rationalism towards dominance because of two interrelated processes. First, it is difficult to reach the high levels of steep hierarchies, especially if they are competence-based. In such a situation, the targeting of high-status individuals using force can accelerate status advancement because it is easier than the alternative: To accrue the necessary competences in order to advance through prestige. Second, as status-competition intensifies, group-based competition becomes more important. To facilitate this, group members may come to highlight (or "essentialize") group differences, which in itself will make rational exchange of argument less likely. Thus, a key requirement for liberal discourse is the recognition of a shared faith and a common humanity (Popper, 1945).

\section{Towards depolarized societies}

Understanding the psychological and structural roots of extreme discontent is key if we are to move towards more peaceful societies. An exclusive focus on populism might lead to the expectation that the roots of discontent are value-based. For example, the rise of right-wing populism may suggest that frustrations are rooted in a decreasing respect for authorities and traditional forms of life. If that was indeed the case, a depolarized society might be reached only 
if non-populists were willing to compromise on important political values and to a larger extent embrace tradition and authority.

In contrast, the present arguments and results suggest that the true roots of the most extreme forms of discontent are less based on a conflict of abstract political values and more on a lack of social status and recognition. If so, the path towards depolarization lies in more inclusion and more equality, for example, based on an affirmation of the classical liberal doctrine of the importance of open, non-dominant exchange of arguments (Popper, 1945). Unfortunately, this is not something that can be fixed quickly, as would be the case if discontent was rooted in transient factors such as the behavior of social media algorithms. Rather, depolarization requires difficult structural changes that alleviates the onset of dominance motivations.

Inclusive structural changes can take two different forms (Iversen \& Soskice, 2019). Inclusion can be facilitated economically by investing in universal access to public education. Inclusion can also be facilitated politically by including marginalized and frustrated voices in the political process. Educational investment generates opportunities for the marginalised and the embrace of discontented groups allows for political representation, in turn de-radicalising the groups and their followers. It will always be difficult to reach out to those with extreme viewpoints and this is especially true in an environment of intense political polarization. In essence, the key challenge of our time is to recognize the frustrations of extremists and to do so in a way that stands firm on democratic principles.

\section{Literature}

Alderson, A. S., \& Nielsen, F. (2002). Globalization and the great U-turn: Income inequality trends in 16 OECD countries. American Journal of Sociology, 107(5), 1244-1299. 
Archer, J., \& Coyne, S. M. (2005). An integrated review of indirect, relational, and social aggression. Personality and Social Psychology Review, 9, 212-230

Ashton, M. C., Lee, K., Pozzebon, J. A., Visser, B. A., \& Worth, N. C. (2010). Status-driven risk taking and the major dimensions of personality. Journal of Research in Personality, 44(6), 734-737.

Baek, Y. M., Wojcieszak, M., \& Delli Carpini, M. X. (2012). Online versus face-to-face deliberation: Who? Why? What? With what effects? New Media and Society, 14(3), 363383.

Bakker, B. N., Rooduijn, M., \& Schumacher, G. (2016). The psychological roots of populist voting: Evidence from the United States, the Netherlands and Germany. European Journal of Political Research, 55(2), 302-320.

Bartusevicius, H., van Leeuwen, F., \& Petersen, M. (2020). Dominance-driven autocratic political orientations predict political violence in non-WEIRD and WEIRD samples. Psychological Science, forthcoming.

Bor, Alexander, and Michael Bang Petersen. 2019. The Psychology of Online Political Hostility: A Comprehensive, Cross-National Test of the Mismatch Hypothesis. PsyArXiv Working Paper.

Castanho Silva, Bruno, Ioannis Andreadis, Eva Anduiza, Nebojsa Blanusa, Yazmin Morlet Corti, Gisela Delfino, Guillem Rico, Saskia P. Ruth, Bram Spruyt, Marco Steenbergen, and Levente Littvay. 2018. "Public Opinion Surveys: a New Scale". In: The Ideational Approach to Populism: Theory, Method \& Analysis, edited by Kirk A. Hawkins, Ryan Carlin, Levente Littvay, and Cristóbal Rovira Kaltwasser. London: Routledge. 
Cheng, Joey T., Jessica L. Tracy, Tom Foulsham, Alan Kingstone, and Joseph Henrich. 2013. Two Ways to the Top: Evidence That Dominance and Prestige Are Distinct yet Viable Avenues to Social Rank and Influence. Journal of Personality and Social Psychology 104:103-25

Coppock, A., \& McClellan, O. A. (2019). Validating the demographic, political, psychological, and experimental results obtained from a new source of online survey respondents. Research \& Politics. https://doi.org/10.1177/2053168018822174

Dawkins, R. (1976). The selfish gene. Oxford university press.

De Dreu, C. K., Gross, J., Méder, Z., Giffin, M., Prochazkova, E., Krikeb, J., \& Columbus, S. (2016). In-group defense, out-group aggression, and coordination failures in intergroup conflict. Proceedings of the National Academy of Sciences, 113(38), 10524-10529.

De Waal, F. B. (1996). Good natured. Harvard University Press.

Dunn, K. (2015). Preference for radical right-wing populist parties among exclusive-nationalists and authoritarians. Party Politics, 21(3), 367-380.

Fessler, Daniel MT, and Colin Holbrook. "Synchronized behavior increases assessments of the formidability and cohesion of coalitions." Evolution and Human Behavior 37.6 (2016): 502509

Glowacki, Luke, and Chris von Rueden. 2015. Leadership Solves Collective Action Problems in Small-Scale Societies. Philosophical Transactions of the Royal Society B: Biological Sciences 370:20150010.

Graham, M.H. Self-Awareness of Political Knowledge. Polit Behav 42, 305-326 (2020). https://doi.org/10.1007/s11109-018-9499-8 
Grubbs, J. B., Warmke, B., Tosi, J., James, A. S., \& Campbell, W. K. (2019). Moral grandstanding in public discourse: Status-seeking motives as a potential explanatory mechanism in predicting conflict. PloS one, 14(10), e0223749.

Gøtzsche-Astrup, O. (2019). Personality moderates the relationship between uncertainty and political violence: Evidence from two large US samples. Personality and individual differences, 139, 102-109.

Horowitz, D. L. (2001). The deadly ethnic riot. Univ of California Press.

Iversen, T., \& Soskice, D. (2019). Democracy and prosperity: Reinventing capitalism through a turbulent century. Princeton University Press.

Kitschelt, Herbert. 2002. Popular dissatisfaction with democracy: populism and party systems. In Democracies and the populist challenge. Springer pp. 179-196.

Kriesi, H., \& Schulte-Cloos, J. (2020). Support for radical parties in Western Europe: Structural conflicts and political dynamics. Electoral Studies, 65, 102138.

Laustsen, L., \& Petersen, M. B. (2015). Does a competent leader make a good friend? Conflict, ideology and the psychologies of friendship and followership. Evolution and Human Behavior, 36(4), 286-293.

Laustsen, L., \& Petersen, M. B. (2017). Perceived conflict and leader dominance: Individual and contextual factors behind preferences for dominant leaders. Political Psychology, 38(6), $1083-1101$.

Levitsky, S., \& Ziblatt, D. (2018). How democracies die. Broadway Books.

Lopez, Jesse and Hillygus, D. Sunshine, Why So Serious?: Survey Trolls and Misinformation (March 14, 2018). Available at SSRN: https://ssrn.com/abstract=3131087 or http://dx.doi.org/10.2139/ssrn.3131087 
Malka, A., Lelkes, Y., Bakker, B. N., \& Spivack, E. (2020). Who is open to authoritarian governance within Western democracies? Perspectives on Politics.

Marchlewska, M., Cichocka, A., Panayiotou, O., Castellanos, K., \& Batayneh, J. (2018). Populism as identity politics: Perceived in-group disadvantage, collective narcissism, and support for populism. Social Psychological and Personality Science, 9(2), 151-162.

Martin, G. J., \& Yurukoglu, A. (2017). Bias in cable news: Persuasion and polarization. American Economic Review, 107(9), 2565-99.

Mason, L. (2015). "I disrespectfully agree": The differential effects of partisan sorting on social and issue polarization. American Journal of Political Science, 59(1), 128-145.

Miller, J. M., Saunders, K. L., \& Farhart, C. E. (2016). Conspiracy endorsement as motivated reasoning: The moderating roles of political knowledge and trust. American Journal of Political Science, 60(4), 824-844.

Morris, J. S. (2005). The Fox news factor. Harvard International Journal of Press/Politics, 10(3), 56-79.

Mudde, C., \& Kaltwasser, C. R. (2014). Populism and political leadership. The Oxford handbook of political leadership, 376-388.

Mutz, Diana C. 2016. In-your-face politics: The consequences of uncivil media. Princeton University Press.

Neal, Z. P. (2020). A sign of the times? Weak and strong polarization in the US Congress, 19732016. Social Networks, 60, 103-112.

Norris, P., \& Inglehart, R. (2019). Cultural backlash: Trump, Brexit, and authoritarian populism. Cambridge University Press. 
Osmundsen, Mathias, Alexander Bor, Peter Bjerregaard Vahlstrup, and Michael Bang Petersen. 2020. Partisan Polarization Is the Primary Psychological Motivation behind “ Fake News " Sharing on Twitter. PsyArXiv Working Paper.

Petersen, M. B. (2020). The Evolutionary Psychology of Mass Mobilization: How Disinformation and Demagogues Coordinate Rather Than Manipulate. Current Opinion in Psychology, forthcoming.

Petersen, M. B., \& Laustsen, L. (2019). Upper-body strength and political egalitarianism: Twelve conceptual replications. Political Psychology, 40(2), 375-394.

Petersen, M. B., \& Laustsen, L. (2020). Dominant leaders and the political psychology of followership. Current opinion in psychology, 33, 136-141.

Petersen, Michael Bang, Mathias Osmundsen, and Kevin Arceneaux. 2020. "The "need for Chaos" and Motivations to Share Hostile Political Rumors" PsyArXiv. doi:10.31234/osf.io/6m4ts

Popper, K. R. (1945). The open society and its enemies. Princeton University Press.

Rico, G., Guinjoan, M., \& Anduiza, E. (2017). The emotional underpinnings of populism: How anger and fear affect populist attitudes. Swiss Political Science Review, 23(4), 444-461.

Salmela, M., \& von Scheve, C. (2017). Emotional roots of right-wing political populism. Social Science Information, 56(4), 567-595.

Sibley, C. G., Wilson, M. S., \& Duckitt, J. (2007). Effects of dangerous and competitive worldviews on right-wing authoritarianism and social dominance orientation over a fivemonth period. Political Psychology, 28(3), 357-371.

Sidanius, J., \& Pratto, F. (2001). Social dominance: An intergroup theory of social hierarchy and oppression. Cambridge University Press. 
Sniderman, P. M., Petersen, M. B., Slothuus, R., \& Stubager, R. (2014). Paradoxes of liberal democracy: Islam, Western Europe, and the Danish cartoon crisis. Princeton University Press.

Sprong, S., Jetten, J., Wang, Z., Peters, K., Mols, F., Verkuyten, M., .. Wohl, M. J. A. (2019). “Our Country Needs a Strong Leader Right Now": Economic Inequality Enhances the Wish for a Strong Leader. Psychological Science, 30(11), 1625-1637.

Tooby, J., Cosmides, L., \& Price, M. E. (2006). Cognitive adaptations for n-person exchange: the evolutionary roots of organizational behavior. Managerial and Decision Economics, 27(2-3), 103-129.

Turchin, P. (2016). Ages of discord. Chaplin, CT: Beresta Books.

von Rueden, Christopher, Michael Gurven, and Hillard Kaplan. 2011. Why Do Men Seek Status? Fitness Payoffs to Dominance and Prestige. Proceedings of the Royal Society B: Biological Sciences 278:2223-32.

Vosoughi, S., Roy, D., \& Aral, S. (2018). The spread of true and false news online. Science, 359(6380), 1146-1151.

Zerjal, Tatiana, et al. "The genetic legacy of the Mongols." The American Journal of Human Genetics 72.3 (2003): 717-721. 